\title{
Prophylaxis and management of postoperative complications after tracheobronchial surgery
}

\author{
Corinna Ludwig \\ Department of Thoracic Surgery, Florence Nightingale Hospital, Düsseldorf, Germany \\ Correspondence to: Corinna Ludwig, MD. Department of Thoracic Surgery, Florence Nightingale Hospital, Kreuzbergstr. 79 , 40489 Düsseldorf, \\ Germany. Email: ludwigc@kaiserswerther-diakonie.de.
}

\begin{abstract}
Prevention of bronchial complications after airway surgery must be our primary goal. Understanding bronchial and anastomotic healing is the first step to success. This can be improved by standardizing operating technique (bronchial closure and end-to-end anastomosis) as well as postoperative care. Bronchopleural fistula after pneumonectomy still remains a feared complication with a high mortality rate. Especially after sleeve resection interpretation of endobronchial healing and postoperative measures of care with the help of an algorithm, may avoid anastomotic insufficiency and therefore reduced the secondary pneumonectomy rate.
\end{abstract}

Keywords: Bronchial stump closure; bronchial anastomosis

Submitted Feb 25, 2020. Accepted for publication Mar 22, 2020.

doi: $10.21037 /$ jtd.2020.03.63

View this article at: http://dx.doi.org/10.21037/jtd.2020.03.63

\section{Aspects on bronchial healing}

Thorough understanding of bronchial anatomy and healing is mandatory for prevention of any type of postoperative airway complications. First of all, we must be aware of tracheobronchial vascularization. Blood supply of the cervical trachea comes mainly from the inferior thyroid artery. The thoracic trachea has a more variable blood supply which may come from the vertebral artery, the subclavian artery and the supreme intercoastal artery. The lower trachea is nourished by the internal thoracic artery whereas the bifurcation and main bronchi are vascularized by the superior and middle bronchial artery arising directly from the thoracic aorta (1). During airway surgery or lymph node dissection these vessels are divided which may partially or completely compromise bronchial blood perfusion.

The first large animal study by Rienhoff $e t a l$. in 1942, demonstrated that bronchial healing 4 weeks after pneumonectomy can be considered as "primary healing" at the edge of the bronchial stump in only $18 \%$. Far more often $(57 \%)$ bronchial healing is a combination of primary healing at the stump and secondary healing from the surrounding tissue (2). His conclusions from macroscopic and histological analysis of the bronchial stump, was that the sutures cut through the bronchial wall, no matter what suture technique was applied, resulting in secondary healing from the surrounding structures. In a similar experiment Smith et al. showed that better results with less bronchopleural fistula could be obtained by mechanical staplers (3). The explanation for this is that primary healing of the bronchial stump only occurs at the firmly adapted edge of the bronchial stump from the mucosa and submucosa not at the more proximal suture line. As early as 7 days after resection neo-angiogenesis at the edge of the bronchial stump promotes revascularization and healing (4).

Healing of the bronchial anastomosis after complete circumferential sleeve resection is always accompanied by ischemia of the distal end of the bronchus, as it's blood supply has been interrupted. Again, healing relies on primary healing at the distal bronchial mucosa and secondary healing from the surrounding tissue.

\section{Suture material and technical aspects of bronchial closure/anastomosis}

The bronchial stump is adapted by an airtight closure of 
Table 1 Classification of the tracheobronchial anastomosis

\begin{tabular}{ll}
\hline Grade & Anastomosis on day 7 after sleeve resection \\
\hline $\mathrm{X}$ & Unknown \\
1 & Healing well, no fibrin deposits \\
2 & Focal fibrin deposits, superficial (mucosal) necrosis \\
3 & Circular fibrin deposits, superficial (mucosal) necrosis \\
4 & $\begin{array}{l}\text { Transmor ischemia of the distal mucosa } \\
5\end{array}$ \\
\hline
\end{tabular}

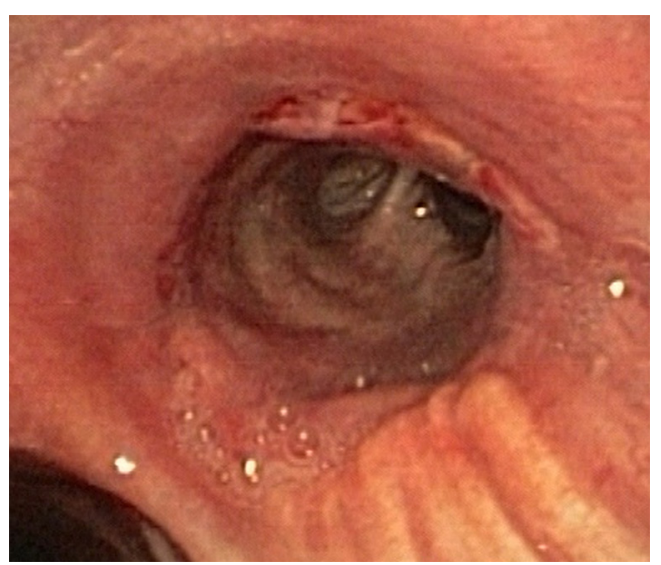

Figure 1 Grade 1: healing well, no fibrin deposits.

the bronchus. This can be achieved by a manual running/ interrupted suture or a mechanical stapling device. In an experimental animal model, the initial stability to pressure of the different suture techniques was equivalent with a slight advantage for stapling devices $(5,6)$. Several older studies have shown that the more surface the suture material provides (silk > catgut $>$ staples), the more inflammatory tissue will be formed. Inflammatory tissue means less stability of the tissue at the end of the bronchus (7). Here again, stapled closure was slightly better, showing less inflammatory tissue and therefore more stable bronchial healing. al-Kattan et al. demonstrated in a large series of 503 pneumonectomies that bronchial stump closure with a nonabsorbable running suture could reduce the rate of bronchial pleural fistula to $1.3 \%$ (8). When comparing the stability of monofilament running sutures with staplers there was no difference (5).

The technique for complete circumferential airway resection and reconstruction with a tension free end-toend anastomosis was technically improved by avoiding telescoping technique which impairs healing of the bronchial ends face to face at the mucosa $(9,10)$ and by changing from an interrupted suture technique to a single running suture technique (11). These simple changes reduced the incidence of anastomotic complications from $19 \%$ to $4 \%$ in lung transplantation. Nevertheless, interrupted suture is still preferred in several centers to adapt bronchi of size difference. But as we gain experience with minimally invasive (VATS) sleeve resection, ongoing discussion on whether interrupted suture is better than single running suture have become obsolete $(12,13)$.

\section{Healing of the bronchial anastomosis}

Postoperative bronchoscopic control of bronchial healing after sleeve resection can be performed on the $7^{\text {th }}$ POD to assess and document endobronchial healing with the help of a five-step classification (Table 1) (14). This early bronchoscopic classification was developed to document the intensity of ischemic necrosis and infection during the critical phase of bronchial healing after sleeve resection. Early awareness of an anastomosis at risk and rapid intervention may prevent more severe complications.

In about half the patients, the bronchial anastomosis heals by primary intention without signs of ischemia (Figure 1: grade 1). In the other half, depending on the grade of ischemia, the bronchial wall shows different depths of injury. The endobronchial mucosa is the most sensitive part of the bronchial wall, showing partial or circumferential fibrin deposits and necrosis, mainly in the proximal part of the distal bronchus (Figure 2: grade 2). As ischemia proceeds, the distal mucosa may show signs of submucosal bleeding and atrophy that may extend into the segmental bronchi (Figure 3: grade 3). Followed by complete necrosis of the bronchial wall with softening of the connective tissue. This can be detected at bronchoscopy by an instability of the distal bronchus in relation to the central airways when the patient coughs (Figure 4: grade 4). Unless revascularization occurs from the surrounding tissue in this very critical phase, necrosis will proceed to perforation into the mediastinum or pleural cavity (Figure 5: grade 5).

\section{Prevention of postoperative disorders}

Factors compromising bronchial healing are local ischemia (reduced blood supply to the bronchus after lymph node dissection) and infection. Yamamoto et al. investigated mucosal blood flow with a laser doppler at the surgical site 


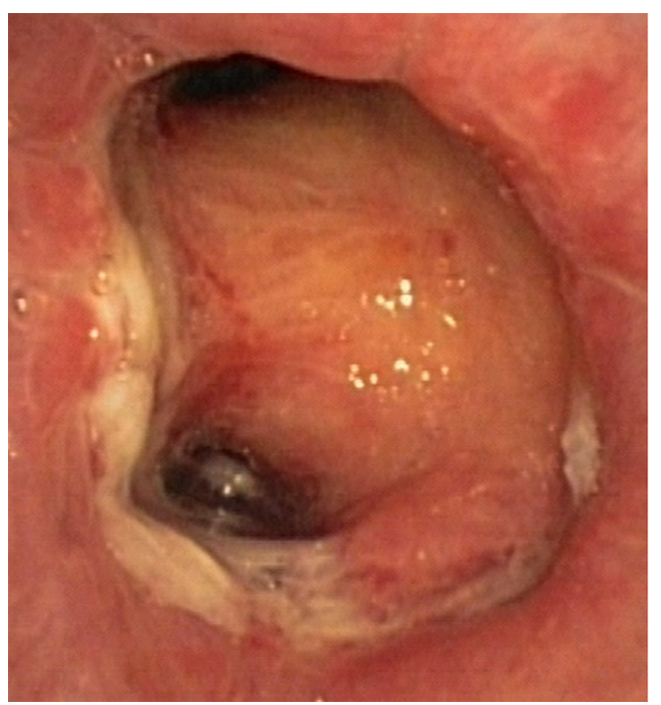

Figure 2 Grade 2: focal fibrin deposits, superficial (mucosal) necrosis.

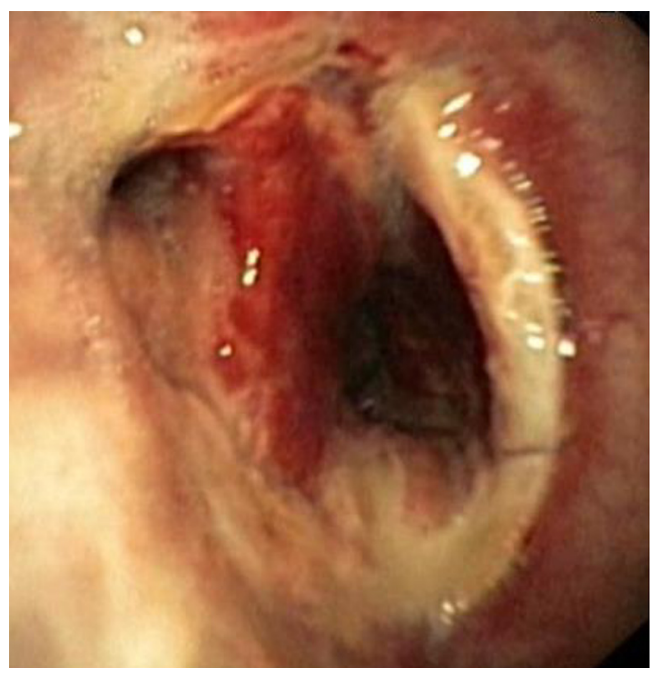

Figure 3 Grade 3: circular fibrin deposits, superficial necrosis and/ or ischemia of the distal mucosa.

of the bronchus pre-, intra- and postoperatively (POD $8-10)$ in patients who had no preoperative therapy, after chemotherapy with and without radiotherapy (15). In patient with no preoperative therapy or chemotherapy change in mucosal blood flow was low and healing was satisfactory. In patients after radiotherapy, preoperative mucosal blood flow was $70 \%$ lower than in those without preoperative therapy and decreased further after surgery. Healing of the bronchus was poor. The authors confirmed

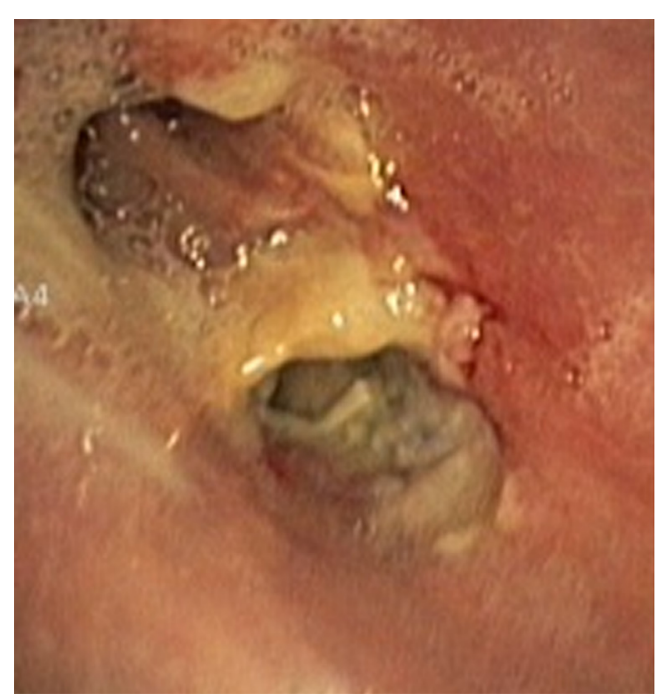

Figure 4 Grade 4: transmural necrosis with instability of the anastomosis.

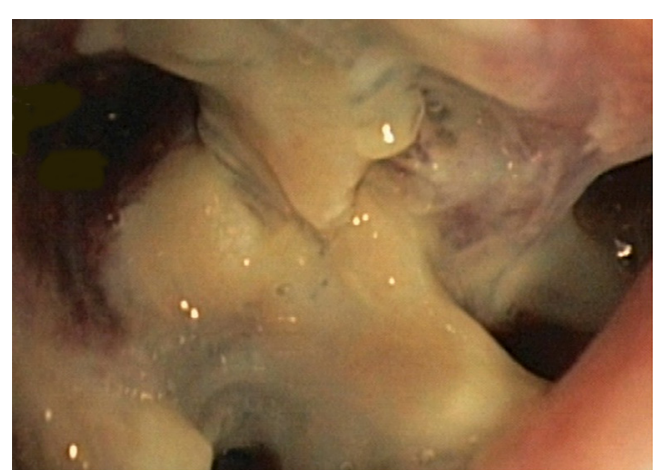

Figure 5 Grade 5: perforation, necrosis of the anastomosis, insufficiency.

that preoperative radiotherapy adversely affects bronchial mucosal blood flow and healing of the bronchial stump. A similar effect was demonstrated by Koryllos et al., neoadjuvant chemoradiation had an adverse influence on bronchial anastomosis healing whereas neoadjuvant chemotherapy alone did not (16).

Pulmonary infections are highly involved in pulmonary complications after lung surgery. Microbial airway colonization, which is found in $10 \%$ to $83 \%$, could be the predisposing factor (17). The combination of local ischemia and infection of the bronchial stump or anastomosis may be the main cause for bronchopleural fistula/anastomostic insufficiency. Prophylactic use of Tobraymycin ${ }^{\circledR}$ inhalation has been proposed to protect the 


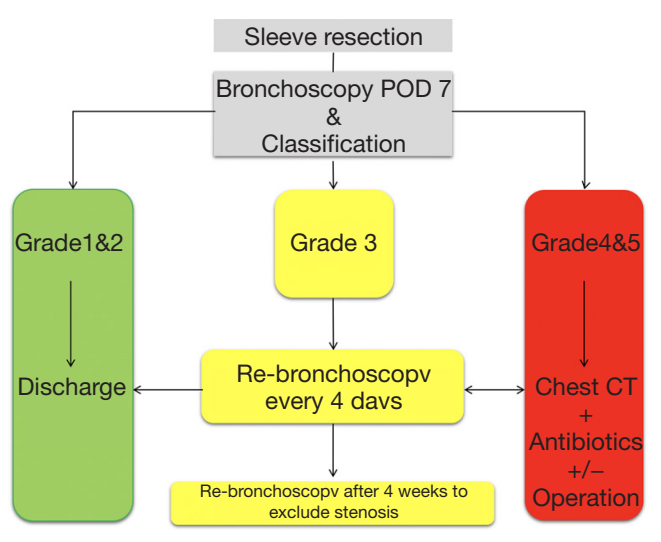

Figure 6 Treatment algorithm according to bronchoscopic classification of the anastomosis after tracheobronchial sleeve resection on POD 7.

bronchus in the first 7 postoperative days. A positive effect on bronchial healing was documented (18).

Covering the bronchial stump after right sided pneumonectomy or sleeve resection is controversely discussed. Coverage using a free pericardial fat pad has been proven to be a simple effective method (19). In an animal model Carbognani et al. performed a histological and imunnohistological analysis and comparison of intercostal muscle, diaphragmatic muscle flap and pericardial fat pad (20). All three had angiogenetic capacities, producing new vessels around the bronchial stump, but the muscle flaps were statistically the best in terms of angiogenesis. Shoji et al. demonstrated the angiogenic ability that the pericardial fat pad, which supports bronchial healing in the early postoperative phase after lung resection (21).

\section{Management of postoperative complications after tracheobronchial surgery}

Bronchial complications occurring in the early phase ( $<7$ days) are frequently due to a technical failure. Sudden increased leakage over the chest tube, subcutaneous emphysema with signs of infection should raise the clinical suspicion of bronchial insufficiency/anastomostic insufficiency, which must be confirmed by bronchoscopy. In such cases reoperation with resuturing of the bronchial stump or bronchial anastomosis and covering the bronchus/ anastomosis with vital tissue is mandatory to support secondary healing.

Late complications (>7 days) are much more complex, they are a combination of surgical trauma at the bronchus, ischemia and local infection. The infection of the thoracic cavity is a feared complication with an incidence of $1.5 \%$ to $28 \%$ in the literature $(22,23)$. Depending on at what point in time the diagnosis of a bronchial complication is made, treatment may be as simple as a chest tube drainage and antibiotics up to reoperation with secondary pneumonectomy.

Diagnosis of late bronchial insufficiency is confirmed by computed tomography of the chest and bronchoscopy. If the bronchial fistula and the cavity insufficient bronchial stump is small and covered by the surrounding tissue of the lung and the mediastinum, then a local drainage with antibiotics may be sufficient.

Bronchopleural fistula after pneumonectomy is more frequent on the right side than on the left side as the left main bronchus is protected within the mediastinum covered by the surrounding aorta and oesophagus. Bronchopleural fistula due to a too long right bronchial stump after pneumonectomy for example, that is no longer covered by mediastinal tissue, conservative managed is usually not an option. Initial therapy consists of drainage of the infected thoracic cavity and antibiotics to protect the contralateral lung. Once the patient is stabilized definitive closure of the bronchial stump is the goal of the treatment. At first the thoracic cavity must be cleaned. The Clagett procedure was described with serial operative debridement and antiseptic towels until the thoracic cavity as a possibility (24). The bronchopleural fistula will require muscle flap closure at some point depending on the size of the fistula. More recently negative pressure vacuum-assisted devices (VAC) have been applied to avoid a temporary thoracic window and thoracoplasty in these fragile patients (25). This method promotes granulation tissue formation, decreases bacterial wound load and wound volume reduction. Once the thoracic cavity is entirely covered with granulation tissue, the microbiologic findings are negative, and the bronchopleural fistula has healed then definitive closure of the chest cavity is possible. Mortality rate of post pneumonectomy bronchopleural fistula remain high, it lies between 29\% and 79\% (26) (27). Prevention must therefore be our main goal.

To prevent anastomotic insufficiency, a critical anastomosis (grade 3 or more) on POD 7 will receive extra attention according to a standardized algorithm (Figure 6). Similarly, to bronchial stump insufficiency, if the anastomosis is covered by surrounding tissue conservative treatment as described above will be applied (Figure 7). 


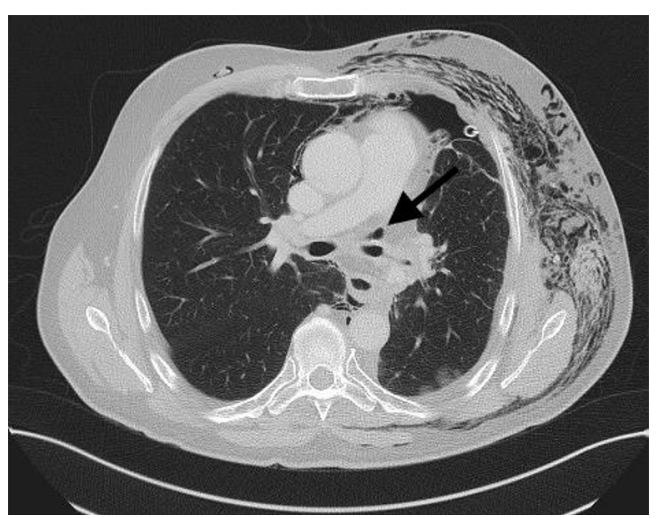

Figure 7 Insufficiency of the bronchial anastomosis after left lower lobe sleeve lobectomy. Air in the mediastinum (see arrow). The lung is fully expanded and covers the anastomosis.

Only if the remaining lung cannot expand or anastomotic perforation into the pleural cavity is identified reoperation with secondary pneumonectomy and treatment of the infected chest cavity is necessary. Since the introduction of a standardized postoperative care after tracheobronchial sleeve resection the rate of secondary pneumonectomy was reduced to $0.6 \%$ (18).

If the anastomosis was classified as grade 3 or more bronchoscopy should be performed to after 4 weeks to exclude stenosis.

\section{Acknowledgments}

Funding: None.

\section{Footnote}

Provenance and Peer review: This article was commissioned by the Guest Editor (Servet Bölükbas) for the series "Airway Surgery", published in Fournal of Thoracic Disease. This article has undergone external peer review.

Conflicts of Interest: The author has completed the ICMJE uniform disclosure form (available at http://dx.doi. org/10.21037/jtd.2020.03.63). The series "Airway Surgery" was commissioned by the editorial office without any funding or sponsorship. The authors have no other conflicts of interest to declare.

Ethical Statement: The author is accountable for all aspects of the work in ensuring that questions related to the accuracy or integrity of any part of the work are appropriately investigated and resolved.

Open Access Statement: This is an Open Access article distributed in accordance with the Creative Commons Attribution-NonCommercial-NoDerivs 4.0 International License (CC BY-NC-ND 4.0), which permits the noncommercial replication and distribution of the article with the strict proviso that no changes or edits are made and the original work is properly cited (including links to both the formal publication through the relevant DOI and the license). See: https://creativecommons.org/licenses/by-nc-nd/4.0/.

\section{References}

1. Salassa JR, Pearson BW, Payne WS. Gross and microscopical blood supply of the trachea. Ann Thorac Surg 1977;24:100-7.

2. Rienhoff WF, Gannon J, Sherman I. Closure of the Bronchus Following Total Pneumonectomy: Experimental and Clinical Observations. Ann Surg 1942;116:481-531.

3. Smith DE, Karish AF, Chapman JP, et al. Healing of the Bronchial Stump after Pulmonary Resection. J Thorac Cardiovasc Surg 1963;46:548-56.

4. Stoelben E, Harpering H, Haberstroh J, et al. Heterotopic transplantation of cryopreserved tracheae in a rat model. Eur J Cardiothorac Surg 2003;23:15-20.

5. Ludwig C, Stoelben E, Schuttler W, et al. A comparison of bronchial closure with the aid of staples or suture: an experimental study on pig tracheae. J Invest Surg 2004;17:93-7.

6. Ludwig C, Behrend M, Hoffarth U, et al. Resistance to pressure of bronchial closures. Comparison of pressure resistance of manual and stapler bronchial closures depending on the angle to the cartilaginous rings. Chirurg 2004;75:896-9.

7. Scott RN, Faraci RP, Goodman DG, et al. The role of inflammation in bronchial stump healing. Ann Surg 1975;181:381-5.

8. al-Kattan K, Cattalani L, Goldstraw P. Bronchopleural fistula after pneumonectomy with a hand suture technique. Ann Thorac Surg 1994;58:1433-6.

9. Garfein ES, Ginsberg ME, Gorenstein L, et al. Superiority of end-to-end versus telescoped bronchial anastomosis in single lung transplantation for pulmonary emphysema. J Thorac Cardiovasc Surg 2001;121:149-54.

10. Garfein ES, McGregor CC, Galantowicz ME, et al. Deleterious effects of telescoped bronchial anastomosis in 
single and bilateral lung transplantation. Ann Transplant 2000;5:5-11.

11. Aigner C, Jaksch P, Seebacher G, et al. Single running suture--the new standard technique for bronchial anastomoses in lung transplantation. Eur J Cardiothorac Surg 2003;23:488-93.

12. Soultanis KM, Gonzalez-Rivas D. Uniportal video-assisted sleeve resections: how to deal with specific challenges. J Thorac Dis 2019;11:S1670-7.

13. Soultanis KM, Chen Chao M, Chen J, et al. Technique and outcomes of 79 consecutive uniportal videoassisted sleeve lobectomies. Eur J Cardiothorac Surg 2019;56:876-82.

14. Ludwig C, Stoelben E. A new classification of bronchial anastomosis after sleeve lobectomy. J Thorac Cardiovasc Surg 2012;144:808-12.

15. Yamamoto R, Tada H, Kishi A, et al. Effects of preoperative chemotherapy and radiation therapy on human bronchial blood flow. J Thorac Cardiovasc Surg 2000;119:939-45.

16. Koryllos A, Lopez-Pastorini A, Zalepugas D, et al. Bronchus Anastomosis Healing Depending on Type of Neoadjuvant Therapy. Ann Thorac Surg 2020;109:879-86.

17. D'Journo XB, Rolain JM, Doddoli C, et al. Airways colonizations in patients undergoing lung cancer surgery. Eur J Cardiothorac Surg 2011;40:309-19.

18. Ludwig C, Riedel R, Schnell J, et al. Inhalation with Tobramycin to improve healing of tracheobronchial reconstruction. Eur J Cardiothorac Surg 2009;35:797-800; discussion 800 .

19. Matsuoka K, Imanishi N, Yamada T, et al. Clinical results of bronchial stump coverage using free pericardial fat pad. Interact Cardiovasc Thorac Surg 2016;23:553-9.

20. Carbognani P, Corradi A, Bobbio A, et al. Histological and immunohistochemical study of the bronchial stump with flap coverage in an animal model. Eur Surg Res 2003;35:54-7.

21. Shoji F, Yano T, Miura N, et al. Pericardial fat pad tissue produces angiogenic factors for healing the bronchial stump. Interact Cardiovasc Thorac Surg 2011;13:271-5.

22. Lois $M$, Noppen $M$. Bronchopleural fistulas: an overview of the problem with special focus on endoscopic management. Chest 2005;128:3955-65.

23. Tapias LF, Ott HC, Mathisen DJ. Complications Following Carinal Resections and Sleeve Resections. Thorac Surg Clin 2015;25:435-47.

24. Zaheer S, Allen MS, Cassivi SD, et al. Postpneumonectomy empyema: results after the Clagett procedure. Ann Thorac Surg 2006;82:279-86; discussion 286-7.

25. Perentes JY, Abdelnour-Berchtold E, Blatter J, et al. Vacuum-assisted closure device for the management of infected postpneumonectomy chest cavities. J Thorac Cardiovasc Surg 2015;149:745-50.

26. Sabanathan S, Richardson J. Management of postpneumonectomy bronchopleural fistulae. A review. J Cardiovasc Surg (Torino) 1994;35:449-57.

27. Kopec SE, Irwin RS, Umali-Torres CB, et al. The postpneumonectomy state. Chest 1998;114:1158-84.
Cite this article as: Ludwig C. Prophylaxis and management of postoperative complications after tracheobronchial surgery. J Thorac Dis 2020;12(10):6179-6184. doi: 10.21037/jtd.2020.03.63 